\title{
A manipulação no discurso religioso
}

Jorge Luís Torresan

Mestre em Lingüística Aplicada pelo Programa de Estudos Pós-Graduados em Lingüística Aplicada e Estudos da Linguagem (LAEL) - PUC-SP; Professor da Graduação e Pós-Graduação - Uninove. São Paulo - SP [Brasil] j-torre@uol.com.br
O discurso religioso é, indubitavelmente, um interessante produto de interações verbais no qual o processo de manipulação pode ser ferramenta importante. Fundamentado nesse princípio, neste artigo, objetiva-se discutir especificamente o discurso produzido pela Igreja Universal do Reino de Deus, com foco no mecanismo de manipulação discursiva.

Palavras-chave: Autoritarismo. Discurso. Manipulação. Sedução. Tentação. 


\section{Introdução}

O discurso religioso tem sido objeto de estudo de várias áreas do conhecimento, em razão de sua complexidade e à sua presença marcante em nossa sociedade. A lingüística, por meio dos vários instrumentos teórico-metodológicos da Análise do Discurso, também contribui muito para elucidar o funcionamento desse discurso, perseguindo a forma como é construído.

Para discutir aspectos lingüísticos do discurso religioso ${ }^{1}$, levemos em consideração o trabalho de Orlandi (1987) no qual encontramos uma possibilidade de tipologia discursiva baseada em dois principais critérios. O primeiro, o da "interação", ou seja, o modo como os interlocutores se consideram; o segundo, o grau de transparência ou de opacidade dos enunciados produzidos, que trata da questão da "polissemia". Assim, diante desses dois critérios, os discursos podem ser classificados, predominante e nunca exclusivamente, como "lúdicos, polêmicos" ou "autoritários".

O lúdico caracteriza-se pelo jogo aberto de interlocuções no qual a relação dialógica entre locutor e interlocutor é dinâmica, com o uso de signos com dimensão múltipla, portanto bastante polissêmico. Exemplo dessa modalidade discursiva é o resultado de uma conversa entre amigos, sem que uma verdade absoluta esteja sendo defendida a todo custo, não ocorrendo, portanto, o cerceamento dos participantes. No discurso polêmico, a relação dialógica entre os interlocutores é mais restrita; aqui os sujeitos envolvidos procuram direcionar seus pontos de vista com menor grau de interação e polissemia. O discurso que permeia uma consulta médica pode ser um exemplo em que encontramos as marcas do polêmico, uma vez que há um momento em que a voz do médico "deve" ser ouvida e aceita, pois é tida como a "detentora" de um saber, cabendo ao paciente aceitá-la por não dominar a linguagem e os procedimentos médicos.

No discurso autoritário, a restrição da relação dialógica entre locutor e interlocutor é muito acentuada, senão completa, o que proporciona a instauração de condições para o exercício da dominação sobre o outro, num quase desaparecimento do "tu". O discurso religioso é exemplo de manifestação em que ocorre a predominância do mecanismo do autoritarismo discursivo. Segundo Citelli (1997, p. 48),

\section{[... ] o paroxismo autoritário chega a tal grau de requinte que o eu enunciador não pode ser questionado, visto ou analisado; é ao mesmo tempo o tudo e o nada. A voz de Deus plas- mará todas as outras vozes, inclusive daquele que fala em seu nome: o pastor.}

O ponto crucial do discurso autoritário é o que Orlandi (1987) chama de ilusão da reversibilidade. Enquanto em alguns discursos se abre a possibilidade para que haja a troca no processo comunicativo, no discurso religioso essa reversão é muito restrita (ou totalmente impossível), pois quem fala é sempre a voz de Deus por meio de seus representantes devidamente autorizados - o Papa, os padres e os pastores -, não havendo, nesse sentido, interação real com o sujeito central do discurso religioso que é Deus. Dessa forma, podemos definir o discurso religioso como aquele em que "[. . . o homem faz falar a voz de Deus" (ORLANDI, 1987, p. 30), de acordo com o seguinte esquema comunicativo:

(A) DEUS (sujeito central do discurso religioso cristão) $=(\mathrm{B})$ PASTOR/PADRE (responsáveis pela transmissão do discurso de A) = (C) POVO/FIEL (apenas um receptor do discurso de B).

\section{Quadro 1}

Fonte: $\mathrm{O}$ autor. 
O problema que há em se fazer porta-voz de Deus é justamente a forma como (B) transmite a (C) o que (A) propõe. O autoritarismo presente no discurso religioso pode ainda ser apoiado pela instauração de um desnivelamento entre o sujeito central Deus e os destinatários desse discurso (o povo/fiel), ambos situados em planos diferentes:

\begin{tabular}{|c|c|}
\hline DEUS & POVO/FIEL \\
(PLANO ESPIRITUAL), & (PLANO MORTAL), por- \\
portanto, & tanto, \\
Imortal & Mortal \\
Eterno & Efêmero \\
Infalível & Falível \\
Infinito & Finito \\
Todo-poderoso & Dotado de poder relativo \\
\hline
\end{tabular}

Quadro 2

Fonte: $\mathrm{O}$ autor.

Esse desnivelamento entre Deus e o fiel, que se traduz por uma relação de subordinação dos ocupantes do plano mortal com o plano espiritual, intensifica a marca do autoritarismo do discurso religioso. O fiel - mortal, efêmero, falível e de poder relativo - possui dois caminhos: ou segue as doutrinas pregadas pelos intermediadores de Deus em troca de uma "salvação", ou adota um regime de vida desvinculado das ideologias divinas pregadas pelos representantes devidamente "autorizados", cometendo, dessa forma, "pecados", tendo como sanção o castigo. O que move o fiel para a salvação é a fé, condição fundamental para alcançar o que foi prometido por Deus e ratificado pelos seus portavozes aqui na terra.

Portanto, podemos sugerir que a ideologia do discurso religioso cristão sustenta-se nas oposições: plano espiritual versus plano mortal; salvação versus castigo; fé versus pecado. Com esta trama ideológica, aqueles que se propõem transmitir a palavra divina têm seguramente a possibilidade de instaurar formas de controle e de manipulação.

Se, por um lado, em meio ao discurso religioso existe a mistificação que envolve o pecado, recoberto figurativamente pela imagem do diabo, do inferno, por exemplo, como elemento intimidador muito forte que produz impacto considerável na crença de boa parte da sociedade de costumes e de posições tradicionais, por outro, há a salvação, recoberta pela figura do céu e da recompensa divina, que constitui uma estimulante tentação para que os fiéis nunca abandonem as doutrinas pregadas. O discurso religioso, tendo em vista esse forte grau de autoritarismo, apresenta aos fiéis um programa de ação firmado no "dever-fazer" mesclado com o "não-dever-fazer", instaurando-se, assim, a interdição (FIORIN, 1988).

Essa é apenas uma das possibilidades de definição do funcionamento do discurso religioso. Contudo, seja qual for a definição que se dê a ele, deparamo-nos sempre com questões que envolvem a forma como os representantes das instituições religiosas falam sobre Deus para os fiéis, que se mostram, em muitos casos, completamente vulneráveis a formas de manipulação.

\section{A manipulação discursiva}

Entre os teóricos e suas respectivas linhas de estudo e de abordagem sobre a linguagem, encontramos a semiótica concebida por A. J. Greimas e pelo Grupo de Investigações Sêmio-Lingüísticas da Escola de Altos Estudos em Ciências Sociais, bastante difundida aqui no Brasil, que nos possibilita um tratamento teórico para a questão da manipulação discursiva. Essa linha teórica parte do princípio de que, para construir o sentido do texto, é preciso 
conceber seu plano de conteúdo sob a forma de um percurso gerativo (BARROS, 1997); portanto, tratase de uma teoria que se preocupa com o texto, sem desconsiderar os elementos contextuais, cuja preocupação é "[...] descrever e explicar o que o texto diz e como ele faz para dizer o que diz."(BARROS, 1997, p. 7).

O percurso gerativo do texto, numa breve exposição ${ }^{2}$, é composto de três níveis que vão do mais profundo, mais abstrato e mais simples, para o mais superficial, mais concreto e complexo; esses níveis são: a estrutura profunda, a narrativa e a discursiva.

No nível fundamental, primeira etapa do percurso gerativo do sentido, temos o ponto de partida da constituição de um texto em que se determina o mínimo de sentido à idéia-célula a partir do qual o texto é constituído. Ao afirmarmos, por exemplo, que um texto trata do amor, da vida, da liberdade etc., estamos analisando justamente o nível fundamental de um texto.

No nível narrativo, segundo momento do percurso gerativo, os valores fundamentais são desenvolvidos do ponto de vista de um sujeito, nível que comporta quatro fases:

a) Manipulação - trata-se de uma forma de ação que o destinador de um discurso exerce sobre seu(s) destinatário(s), a fim de fazê-lo(s) cumprir um programa dado, ou seja, fazer com que o(s) destinatário(s) queira(m) ser ou fazer algo;

b) Competência - devidamente manipulados, $\mathrm{o}(\mathrm{s})$ destinatário(s) recebe(m) do destinador uma qualificação necessária para pôr em prática uma ação. Um exemplo que ilustra essa fase é o que ocorre nos contos de fada em que, para salvar a donzela, o herói sempre precisará de um objeto mágico que lhe possibilite praticar a ação desejada;

c) Performance - manipulado(s) e com competência para agir, o(s) destinatário(s), então, praticam uma ação;

d) Sanção - após a realização da ação, tem-se um resultado que pode ser positivo (uma recompensa), ou negativo (um castigo).

O nível discursivo, o último momento do percurso gerativo, é o patamar mais superficial, o mais próximo do plano de expressão que é o texto. Nesse contexto, as estruturas narrativas convertem-se em estruturas discursivas assumidas pelo sujeito da enunciação, que é o responsável pela projeção dos actantes do discurso, pelas determinações de tempo, de espaço e pelas figuras que recobrem os temas de que trata um texto.

A semiótica greimasiana define a manipulação discursiva como uma ação do homem sobre os outros homens, a fim de que executem um programa dado (GREIMAS; COURTÉS, 1989) por meio, inicialmente, de quatro grandes estratégias: sedução, tentação, intimidação e provocação.

Na sedução, o destinador do discurso trabalha com uma imagem positiva de seus destinatários a fim de fazê-los querer algo (ex.: Você é uma pessoa tão generosa, tão boa, tenho certeza de que vai me ajudar); na provocação, o trabalho do destinador do discurso é com uma imagem negativa dos destinatários (ex.: Livre-se dessa sua imagem de sovina, empreste-me um dinheiro); na tentação, o destinador trabalha com aspectos positivos sobre a ação dos destinatários (ex.: Se você comer toda a verdura, a mamãe leva você ao parque); na intimidação, os aspectos negativos sobre a ação dos destinatários são levados em conta (ex.: Acho melhor você estudar se 
não quiser ser punido). 0 quadro abaixo ilustra o esquema dessas formas de manipulação.

\begin{tabular}{|c|c|c|}
\hline Manipulação por: & $\begin{array}{c}\text { Posição } \\
\text { do destinador }\end{array}$ & $\begin{array}{c}\text { Posição dos desti- } \\
\text { natários desejada } \\
\text { pelo destinador }\end{array}$ \\
\hline Sedução & $\begin{array}{c}\text { Imagem positiva } \\
\text { do destinatário }\end{array}$ & Querer fazer \\
\hline Provocação & $\begin{array}{c}\text { Imagem negativa } \\
\text { do destinatário }\end{array}$ & Dever fazer \\
\hline Tentação & $\begin{array}{c}\text { Imagem positiva } \\
\text { da ação do desti- } \\
\text { natário }\end{array}$ & Querer fazer \\
\hline Intimidação & $\begin{array}{c}\text { Imagem negativa } \\
\text { da ação do desti- } \\
\text { natário }\end{array}$ & Dever fazer \\
\hline
\end{tabular}

Quadro 3

Fonte: $\mathrm{O}$ autor.

Essas quatro formas de manipulação podem ser encontradas em todos os tipos discursivos, pois sempre há, em nossos discursos, propósitos mais ou menos definidos, tais como fazer com que alguém nos dê atenção, vender um produto ou convencer alguém sobre uma verdade. Seja por meio de tentações, intimidações, provocações ou seduções, ou de todas elas mescladas num único discurso, sempre manipulamos a linguagem e, conseqüentemente, tentamos manipular o interlocutor para atingir nossos objetivos.

No discurso religioso, tentação e intimidação parecem ter sido, durante muito tempo, as formas de manipulação dominantes. Tentadora porque, agindo da forma como a doutrina cristã é pregada pelos representantes das igrejas, os fiéis podem alcançar o reino dos céus, e intimidadora porque a não-aceitação do que lhes é pregado conduz a alma humana ao castigo, ao inferno. Contudo, em se tratando do discurso dos representantes da Igreja Universal do Reino de Deus, as estratégias de mani- pulação por tentação e sedução se destacam muito mais, pois intimidar o fiel é uma prática que pode afastá-lo. É muito mais vantajoso destacar o que o fiel pode conquistar de bom para sua vida do que lhe mostrar sempre as portas do inferno.

\section{As formações imaginárias no discurso associadas às formas de manipulação}

Considerando as formas de manipulação, somos levados a assumir como principal ato de linguagem estruturador do discurso - pelo menos de grande parte deles que circula na sociedade - a persuasão que é muito mais incisiva do que o ato de convencer; afinal, "[...] persuadir é mais do que convencer, pois a convicção não passa da primeira fase que leva à ação [...]" (PERELMAN; OLBRECHTS-TYTECA, 1996, p. 30). O locutor de um discurso pode até convencer seu público-alvo sobre um fato, uma idéia, mas para fazer com que esse público ponha em prática suas palavras, é necessária uma força ainda maior que depende de argumentação persuasiva que seja capaz de atingir o espírito e a vontade desse público.

A criação desse efeito de sentido depende de um trabalho com a linguagem que garanta a construção de uma rede discursiva com a qual os interlocutores se envolvam, para fazê-los crer e pôr em prática o que o locutor veicula em seu discurso. Esse fato é observado com mais evidência se voltarmos nossa atenção para alguns discursos como o político (dos períodos eleitorais), o familiar - especificamente o resultado da interação entre mãe e filho - o pedagógico e o religioso. São discursos que trabalham com objetivos muito precisos. A aceitação 
e o pôr em prática o que esses discursos veiculam dependem muito do fazer persuasivo do locutor.

São muitos os mecanismos por meio dos quais o locutor de um discurso - que se torna um locutormanipulador da linguagem - constrói a persuasão, a saber: a seleção lexical, os operadores argumentativos, as informações implícitas (pressupostos e subentendidos), a rede polifônica do discurso, entre outros e as formações imaginárias estabelecidas entre os interlocutores associadas às formas de manipulação.

A finalidade da grande maioria dos discursos, principalmente daqueles com força persuasiva, é fazer com que os interlocutores creiam no que é veiculado e executem ações. No caso do discurso religioso, esses dois procedimentos são necessários, pois esse discurso é, ao mesmo tempo, de ordem cognitiva e prática, isto é, em primeiro lugar é preciso garantir que os fiéis creiam no que é dito. Para isso, o discurso tem de ser convincente para, em seguida, levar o fiel a agir. Aqui entra em jogo um fator de extrema importância, o estabelecimento da confiança entre os interlocutores. Ao contrário do que ocorre no mundo burocrático dos negócios, em que documentos garantem o cumprimento do que é firmado, para outras formas de interação, a confiança é o único elemento de garantia da verdade. Acreditar naquilo que se diz ou em quem diz algo depende muito da forma como se diz, ou seja, depende da maneira como o locutor põe a linguagem em funcionamento, especificamente da imagem que o locutor faz de si mesmo, de seu interlocutor e de referente do seu discurso.

Nessa análise, os interlocutores são os fiéis seguidores da Igreja Universal do Reino de Deus e os pastores, e o referente é Deus. Assim, levaremos em conta três questões: 1) Que imagem o pastor faz do fiel em seu discurso? 2) Que imagem o pastor faz de si próprio? 3) Que imagem o pastor faz de Deus em seu discurso? Essas questões derivam daquelas propostas por Bakhtin (1997 p. 321) na discussão sobre gênero de discurso. São elas: "A quem se dirige o enunciado? Como o locutor (ou escritor) percebe e imagina seu destinatário? Qual é a força de sua influência sobre o enunciado?".

Os questionamentos aqui propostos são verificados, tendo em vista também a questão da manipulação discursiva tratada anteriormente. Neste artigo, os discursos analisados não foram transcritos na íntegra. Analisaremos apenas os recortes mais significativos de uma série de discursos publicados no jornal Folha Universal - Um jornal a serviço de Deus, de propriedade da Igreja Universal, nas edições de número 371 a 382, referentes ao período de maio a agosto de 1999.

\section{$4 \quad$ A imagem que o pastor faz do fiel}

Consideremos os recortes abaixo:

Discurso 1 (D1)

Prezado leitor, se você crê em um Deus grande, então a sua vida tem que ser proporcional à sua grandeza. Basta crer nisso! Não importa quem você seja nem a vida que teve no passado: Deus não faz distinção entre as pessoas, nem abençoa por merecimento, mesmo porque ninguém é perfeito.

(D2)

De repente você diz: 'Mas eu não tenho nenhuma formação'. E precisa? Pense em quantas pessoas formadas estão por aí, vivendo de favores. As Bênçãos de Deus in-

Dialogia, São Paulo, v. 6, p. 95-105, 2007. 
dependem de qualquer tipo de qualificação desse mundo. O que importa realmente é que creia de todo o coração e se lance de corpo, alma e espírito nessa fé: somente assim o Senhor Jesus poderá ser glorificado pela sua fé.

A Sua palavra diz: 'Do alto me estendeu Ele a mão e me tomou; tirou-me das muitas águas. Livrou-me de forte inimigo e dos que me aborreciam, pois eram mais poderosos do que eu. (Salmos 18.16,17)'. As muitas águas descritas no texto, simbolizam os problemas. De repente você tem se deparado com um inimigo em sua vida financeira, física, familiar ou sentimental; talvez já não tenha mais força e até já se sinta incapaz de lutar. Então, saiba que quando se aproxima de Deus você fica imbuído de uma certeza que lhe faz enxergar os seus problemas de maneira diferente. É essa certeza que lhe concede a vitória.

Nos recortes anteriores, a imagem que o pastor faz do fiel é muito positiva, no que se refere a fazê-lo acreditar que é digno e merecedor de uma vida sem dificuldades em qualquer área: familiar, sentimental, financeira e de saúde. Quando o pastor diz em (D1) que, "[...] se você crê em um Deus grande, então a sua vida tem que ser proporcional à Sua grandeza”, ele incute no fiel a idéia de que deve agir para alcançar as bênçãos divinas. Esse discurso tentador faz com que o fiel não meça esforços para pôr em prática o que lhe é pregado, o que pode leválo ao fanatismo.

Contudo, para conquistar cada vez mais fiéis, não basta apenas abordá-los com um discurso tentador que os faça acreditar que podem alcançar benefícios para as suas vidas por meio da fé, é preciso também seduzi-los, isto é, construir uma imagem positiva desses fiéis como ocorre em (D1) quando o pastor diz que "Não importa quem você seja nem a vida que teve no passado: Deus não faz distinção entre as pessoas nem abençoa por merecimento, mesmo porque ninguém é perfeito", ou em (D2), antecipando um possível questionamento do fiel "De repente você diz: 'Mas eu não tenho nenhuma formação'. E precisa? Pense em quantas pessoas formadas estão por aí, vivendo de favores. As Bênçãos de Deus independem de qualquer tipo de qualificação deste mundo.". Tudo nos indica que a forma de persuadir o fiel para que aceite o que a igreja prega é conduzida por uma constante articulação discursiva que alterna tentação e sedução. Com isso, o fiel, emocionalmente desequilibrado pelos problemas que enfrenta, sente-se encorajado e muito disposto para pôr em prática as doutrinas pregadas pelo pastor.

Em (D3), essa articulação entre tentação e sedução se repete. Nesse trecho, o pastor inicia sua pregação citando um salmo, o que dá mais credibilidade ao seu discurso: "A Sua palavra diz: 'Do alto me estendeu Ele a mão e me tomou; tirou-me das muitas águas. Livrou-me de forte inimigo e dos que me aborreciam, pois eram mais poderosos do que eu. (Salmos 18.16,17)”; em seguida, o pastor propõe uma definição para o salmo: "As muitas águas descritas no texto, simbolizam os problemas." Na seqüência de seu discurso, o pastor exemplifica/concretiza tais possíveis problemas com fatos da vida real do fiel, já deixando implícita a idéia de que ele é debilitado e carente: "De repente, você tem se deparado com um inimigo em sua vida financeira, física, familiar ou sentimental; talvez já não tenha mais força e até já se sinta incapaz de lutar.” Mostrando-se ciente desse 
fato, o pastor, então, tenta seduzir o fiel, incutindolhe a idéia de que ele pode ser um vitorioso: "Então, saiba que quando se aproxima de Deus você fica imbuído de uma certeza que o faz enxergar os seus problemas de maneira diferente. É essa certeza que lhe concede a vitória."

\section{(D4)}

A palavra de Deus afirma: 'Se atentamente ouvires a voz do Senhor, teu Deus, tendo cuidado de guardar todos os seus mandamentos que hoje te ordeno, o Senhor, teu Deus, te exaltará sobre todas as nações da terra. (Deuteronômio 28.I)'. Prezado leitor, veja que existe uma condição para que Deus venha a manifestar o Seu Poder na vida de uma pessoa. Para que as bênçãos possam se concretizar, não basta conhecer os Seus mandamentos, mas, principalmente, guardá-los. E, para fazer isso, é preciso que a pessoa seja forte e corajosa.

A forma como o pastor visualiza o fiel - o fiel que ele deseja - é muito próxima da forma como um publicitário vê um consumidor de um produto.Isso quer dizer que é preciso seduzir esse possível consumidor (fiel), conferindo-lhe algumas características positivas como "forte", "corajoso", e, ao mesmo tempo, tentá-lo por meio do emprego de estratégias que o convençam a adquirir o produto, neste caso específico, o Deus idealizado pela igreja.

Trata-se de um discurso que, a todo momento, tenta fazer com que o fiel saia da esfera do cognitivo e passe para a ação. Como em qualquer outro jogo propagandístico, o locutor de um discurso deve, além de levar em conta a imagem de seu interlocutor, considerar a imagem que faz de si mesmo a fim de conferir maior credibilidade a seu discurso. Vejamos como isso ocorre no discurso aqui analisado.

\section{A imagem que o pastor faz de si próprio}

Mencionou que o fator confiança deve ser estabelecido nas relações discursivas quando o locutor precisa persuadir o interlocutor a compartilhar idéias e/ou ideologias. Nesse sentido, a confiança num determinado discurso está ligada diretamente ao seu locutor, pois geralmente não confiamos no que algumas pessoas nos dizem justamente porque não confiamos na pessoa. Visto que o pastor está servindo de porta-voz de Deus, ele precisa necessariamente construir uma imagem muito positiva de si mesmo, apreendida pelos fiéis como a de alguém que possui conhecimento sobre a palavra de Deus e que sabe interpretar as muitas metáforas encontradas na Bíblia.

(D5)

A seguir, a passagem bíblica relata: 'Assaltaram-me no dia da minha calamidade, mas o Senhor me serviu de amparo. Trouxe-me para um lugar espaçoso; livrou-me porque Ele se agradou de mim' (Salmos 18.18.19). Esta descrição mostra muito bem em quem cremos! Este é o Deus que a Igreja Universal tem apresentado para as pessoas que chegam sofrendo e desesperadas.

(D6)

É por isso que nós da Igreja Universal somos decisivos em nossa fé e não aceita- 
mos o fracasso nem a derrota. O Deus que temos apresentado para o povo é infinitamente grande e poderoso. Ele é o Deus do impossível e tem o desejo de fazer por você muito mais do que possa imaginar.

(D7)

Portanto, a Palavra que temos pregado para você não é para ficar apenas no conhecimento, mas para ser, acima de tudo, praticada; só assim você poderá colher Seus benefícios.

Da mesma forma que o pastor institui a sedução e a tentação quando se dirige ao fiel, ao tratar de si mesmo ele intensifica essa sedução e tentação, como ocorre em (D5), interpretando o mencionado "lugar espaçoso" como sendo as dependências da Igreja Universal. Isso significa que a igreja possui a competência necessária para operar transformações na vida do fiel, independentemente da natureza de seus problemas. É importante ressaltar que, tanto em (D6) quanto em (D7), o pastor emprega a primeira pessoa do plural para tratar de Deus. Esse "nós" inclusivo é importante para habilitar o discurso do pastor - afinal ele é um representante da igreja.

Contudo, apesar da intensa ação discursiva para fazer com que o fiel creia e, principalmente, aja conforme lhe é pregado, o pastor se exime de qualquer responsabilidade, uma vez que ele é apenas o "transmissor facilitador" da palavra de Deus. Caso o fiel não consiga atingir as graças desejadas, a culpa nunca é da igreja ou do pastor que não foram competentes para operar a transformação na vida do fiel. As graças não conquistadas estão diretamente ligadas à intensidade da fé do fiel. Isso pode ser verificado na transcrição abaixo:
(D8)

Se você estiver disposto a sacrificar a Deus o seu tudo, então participe e creia que Deus lhe honrará; mas se você não estiver neste espírito, meu amigo, não participe. Não entre nesta batalha incentivado apenas pelas palavras do pastor ou escorado na fé de um outro irmão da igreja. É justamente porque muitos agem assim que as bênçãos deixam de acontecer. Depois ficam lamentando, culpando o pastor, o bispo, a igreja, dizendo inclusive que nunca foram abençoados em campanha nenhuma.

\section{A imagem que o pastor faz do referente do seu discurso}

Assim como ocorre em todos os discursos das igrejas que cultuam o cristianismo, é de Deus que a Igreja Universal, pelo menos num nível mais superficial, parece tratar ${ }^{3}$. A todo momento é empregado o nome de Deus, mencionados seus feitos aqui na terra, registrados pelo texto bíblico, mas que imagem o pastor faz desse Deus? Que Deus é esse da Igreja Universal?

Evidentemente, essa imagem não pode ser outra senão a muito positiva, contribuindo, assim, para que o fiel se sinta tentado e seduzido a aderir ao discurso da Igreja, passando a ser mais uma ovelha do grande rebanho iurdiano. Vejamos trechos de alguns discursos dos pastores:

(D9)

Esta é a fé que deve estar no seu coração: de que Deus é poderoso para ressuscitar sua família, sua vida financeira, sua saúde, enfim, tudo que está destruído. 
(D10)

Para que esta vontade possa ser correspondida, no entanto, Deus conta com homens de fé, coragem e determinação; homens dispostos a se sacrificar para alcançarem seus propósitos. Não há nada que aproxime mais o ser humano do seu Criador do que a apresentação de uma oferta de qualidade. Prova disso foi o sacrifício oferecido por Deus para salvar a humanidade.

\section{(D11)}

Com esse exemplo fica provado que Deus não aprova a timidez ou o medo, e muito menos pode contar com os tímidos ou medrosos para fazer aquilo que tem de ser feito neste mundo.

o Deus a que se refere o pastor é tão forte e poderoso quanto a própria Igreja Universal do Reino de Deus. Cobrar do fiel uma atitude firme que ponha a fé em prática em termos de sacrifícios decorre do fato de que Deus, segundo o pastor, não aceita tímidos e covardes em seu rebanho. Trata-se de um discurso que institui o desafio; é como se o pastor submetesse à prova o poder de crença e de ação do fiel, o que se pode verificar em (D10) no qual o pastor fala de uma "oferta de qualidade" que o fiel deve oferecer a Deus, por meio da Igreja (a intermediária) para conquistar os milagres, as transformações na vida.

A Igreja Universal cria, em prol de seus objetivos, a imagem de um Deus mercenário que somente concede graças ao fiel mediante demonstração de fé de qualidade que, no âmbito da igreja, significa a doação em dinheiro.

\section{Considerações finais}

A discussão das formações imaginárias que o pastor textualiza em seu discurso sobre si mesmo, sobre o fiel e sobre Deus confirma que a sedução e a tentação são os dois principais expedientes empregados para atrair a atenção do fiel e, ao mesmo tempo, manipulá-la. Com a sedução, o pastor diz, de forma explícita ou implícita, o que ele "sabe" sobre a vida do fiel, seus desejos e anseios, pondo-o numa posição de escolha quase forçada, pois, às vezes, é difícil esquivar- se dos elogios que lhe são feitos por uma pessoa que se apresenta sensível diante dos mais diversos problemas sociais.

Esse envolvimento sedutor é associado à tentação, pois com ela o pastor propõe sempre ao fiel um bem de valor para convencê-lo a fazer o que lhe é solicitado. No caso da Igreja Universal, esses bens são claramente identificados pelo pastor: a transformação da vida do fiel interpretada por ações tais como: elevar padrão financeiro, curar-se de uma doença e livrar-se de problemas sentimentais. Desse modo, vemos que o discurso da Igreja Universal atua com o propósito de provocar, no fiel, a sensação de querer fazer algo e não se sentir obrigado a fazê-lo, o que caracterizaria um discurso provocador e intimidador.

Isso demonstra que o discurso da Igreja Universal não se desenvolve sobre um excessivo autoritarismo suportado pelo "dever", que apenas dita o que deve ser seguido. O pastor da Universal prefere destacar as formas como o fiel pode conquistar concretamente a tão sonhada transformação em sua vida na terra.

Ao contrário de outras, que pedem as contribuições prometendo a recompensa apenas após a morte, a Igreja Universal faz o contrário, ou seja, 
ela exige do fiel a demonstração de sua fé por meio de sacrifícios (doações), com a promessa de recompensa aqui na terra, sob a forma de dinheiro, saúde, felicidade, paz espiritual e familiar etc.

\section{Manipulation in the religious discourse}

The religious discourse is undoubtedly an enticing product of social interactions in which the manipulation process can be an important tool. Based on that theory, this abstract it is aimed to discuss the religious discourse, specifically the one produced by the Universal Church of God's Kingdom, focusing on the discursive manipulation mechanism.

Key words: Authoritarianism. Discursive manipulation. Religious discourse. Seduction. Temptation.

\section{Notas}

1 É importante esclarecer que as considerações aqui propostas sobre o discurso religioso valem para todas as instituições que cultuam os preceitos do cristianismo que exerce uma forte e grande influência em quase todo o mundo.

2 Como neste artigo não se objetiva uma análise exaustiva do funcionamento do percurso gerativo de sentido do texto, as fases que o compõem não serão profundamente definidas. Tratar-se-á com mais atenção, apenas da fase da manipulação, por ser importante para o desenvolvimento das discussões sobre o discurso religioso.
3 No artigo "O ponto de vista enunciativo sobre a linguagem: a modalização no discurso da Igreja Universal do Reino de Deus”, publicado na revista Dialogia, v. 3, p. 87, discute-se a forma como a referida igreja usa as palavras da Bíblia para cultuar uma outra ideologia pregada.

\section{Referências}

BAKHTIN, M. Estética da criação verbal. Tradução de Maria E. Galvão G. Pereira. 2. ed. São Paulo: Martins Fontes, 1997.

BARROS, D. L. P. Teoria semiótica do texto. 3. ed. São Paulo: Ática, 1997.

CITELLI, A. Linguagem e persuasão. 11. ed. São Paulo: Ática, 1997.

FIORIN, J. L. O regime de 1964 - Discurso e ideologia. 1. ed. São Paulo: Atual, 1988.

FOLHA UNIVERSAL. Edições 371 a 382 de maio a agosto de 1999. São Paulo.

GREIMAS, A. J.; COURTÉS, J. Dicionário de semiótica. 9. ed. Tradução de diversos autores. São Paulo: Cultrix, 1989.

ORLANDI, E. P. A Linguagem e seu funcionamento: as formas do discurso. 2. ed. Campinas: Pontes, 1987.

PERELMAN, C.; OLBRECHTS-TYTECA, L. Tratado da argumentação - A nova retórica. Tradução de Maria E. Galvão G. Pereira. São Paulo: Martins Fontes, 1996.

recebido em 14 mar. 2007 / aprovado em 4 set. 2007

Para referenciar este texto:

TORRESAN, J. L. A manipulação no discurso religioso.

Dialogia, São Paulo, v. 6, p. XX-XX, 2007. 
